Case Report

\title{
A Rare Incidental Finding of a Foreign Body in the Nasopharynx during Adenotonsillectomy
}

\author{
Waleed M. Alshehri (iD and Bandar Al-Qahtani \\ Otolaryngology Department, King Saud Medical City, Riyadh 12746, Saudi Arabia \\ Correspondence should be addressed to Waleed M. Alshehri; dr.alyousie@gmail.com
}

Received 4 January 2018; Accepted 27 February 2018; Published 28 March 2018

Academic Editor: I. Todt

Copyright (c) 2018 Waleed M. Alshehri and Bandar Al-Qahtani. This is an open access article distributed under the Creative Commons Attribution License, which permits unrestricted use, distribution, and reproduction in any medium, provided the original work is properly cited.

\begin{abstract}
Diverse foreign bodies may become lodged in the aerodigestive tract, and the discovery of such foreign bodies is an expected scenario for health-care practitioners. The foreign body insertion may be accidental or deliberate, and the object may be organic or inorganic. Most accidental foreign body aspirations occur in children, and some such cases are potential threats that go unnoticed. Very few cases of foreign bodies in the nasopharynx have been reported. Herein, we describe an unusual case in which a foreign body in a child's nasopharynx went unnoticed for 1 year and was detected intraoperatively.
\end{abstract}

\section{Introduction}

The peer-reviewed literature contains reports of over 12,000 pediatric cases of aspirated foreign bodies that required bronchoscopic removal [1]. Clinical suspicion is initially based on the patient's history, the reported symptoms, and an objective chest evaluation $[2,3]$ incorporating X-ray imaging and airway fluoroscopy [4-6]. Bronchoscopy is used to establish a definitive diagnosis $[7,8]$, and a rigid bronchoscope is the ideal tool for removal [9-11].

Multiple retrospective series studies of pediatric foreign body aspiration have helped in the epidemiological characterization of this condition [1, 9, 12-18]. The lodgment sites of aspirated foreign bodies are diverse. Eren et al. [14] reviewed over 1,000 pediatric cases of foreign body aspiration and reported that the bronchoscopically detected lodgment sites included the larynx (3\%), trachea (13\%), right main bronchus or distal branch (60\%), and left main bronchus or distal branch (23\%). However, the nasopharynx is a rare lodgment site for foreign bodies and hardly receives a passing mention even in standard comprehensive textbooks [19]. Herein, we describe a rare pediatric case of nasopharyngeal lodgment of an aspirated foreign body.

\section{Case Presentation}

A 4-year-old girl was admitted to undergo an elective adenotonsillectomy as a day surgery patient. The child had been experiencing recurrent adenotonsillitis and snoring. She had unremarkable nose and ear examination results and grade 2 tonsils according to the Brodsky scale. She underwent a routine preoperative assessment in which all laboratory test results were normal. However, an adenoid X-ray examination showed posterior nasopharyngeal soft tissue that was indenting and narrowing the nasopharyngeal air column (Figure 1), which suggested adenoid hypertrophy. We observed a faint soft tissue structure $(19 \mathrm{~mm} \times 13 \mathrm{~mm})$ in the oropharynx. The soft tissue shadows of the epiglottis and the cervical spine, and the prevertebral soft tissue shadow, all looked normal. When we examined the nasopharynx with a mirror to visualize the adenoid tissue, we observed a foreign body in the choanae.

We removed the foreign body with curved artery forceps. We found that the specimen was a rubber swimming earplug for adults (Figure 2). The adenotonsillectomy was continued as planned with no intraoperative complications, and the patient was discharged later that day. 


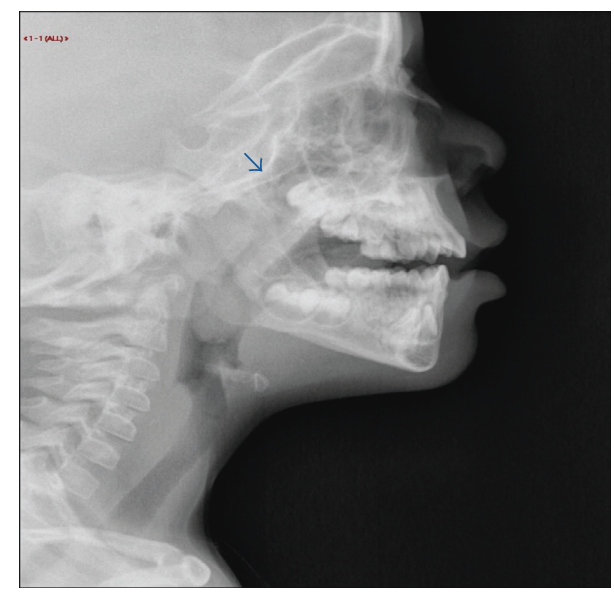

Figure 1: Soft tissue X-ray image showing adenoid enlargement.

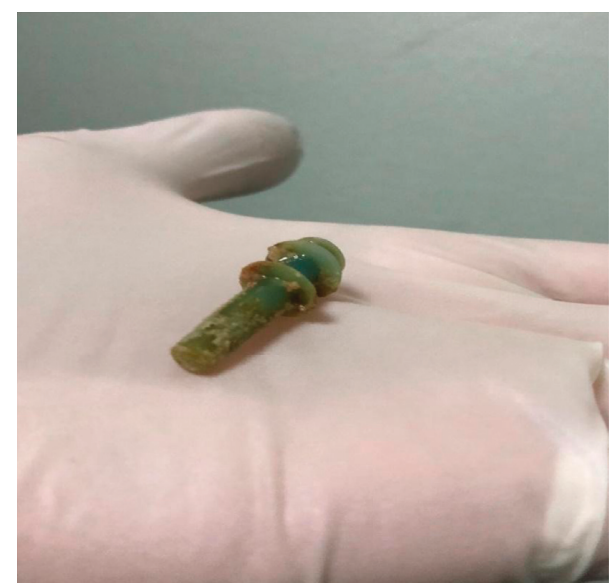

(a)

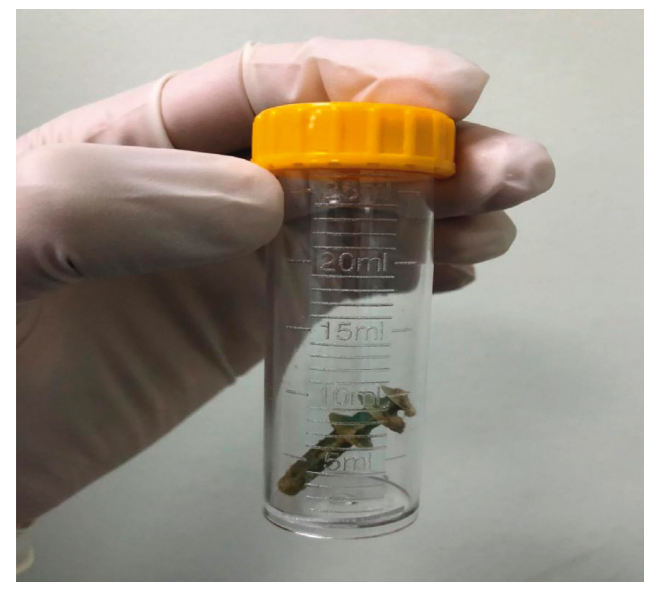

(b)

FIGURE 2: Foreign body after removal.

After the operation, we asked the patient's mother about the foreign body, and she mentioned that her daughter had experienced a brief choking episode 1 year earlier. She had taken the child to a pediatric emergency room unaware that she had aspirated a foreign body. The emergency room physicians had obtained an X-ray image but observed no otolaryngologic irregularities. The child had been discharged later the same day in good condition.

The child's mother provided consent for the publication of this case report.

\section{Discussion}

Children who aspirate foreign bodies present with signs and symptoms that are mostly nonspecific, and in cases of unwitnessed aspiration, the diagnosis can be delayed, which increases morbidity and the likelihood of chronicity [20]. Children younger than 36 months have a normal developmental curiosity and independence associated with reduced parental supervision. Altogether, these factors place them at an increased risk of foreign body aspirations; this age group has been shown to account for approximately $75 \%$ of reported cases $[21,22]$. A positive suggestive history of aspiration is less likely in long-standing cases of otolaryngologic irregularities, with the likelihood of foreign body aspiration reportedly ranging from $53 \%$ to $77 \%[23,24]$. Despite the voluminous literature addressing pediatric foreign body aspiration, few studies have examined the clinical characteristics of cases involving delayed presentation $[25,26]$.

The nasopharynx is an uncommon lodgment site for foreign bodies. This was confirmed by our literature search, which revealed very few reports of nasopharyngeal foreign body lodgment. The reported cases involved small objects such as a ring [27], a tooth [28], a leech [29], and even a fish [30]. Nasopharyngeal foreign body lodgment can occur in many scenarios, such as dislocation of a foreign body from the nasal cavity during extraction attempts, upward migration from the pharynx or esophagus after forceful pressure due to vomiting or coughing, traumatic penetration, or iatrogenic causes [30]. The clinical presentation of nasopharyngeal foreign body aspiration may mimic other common pediatric conditions such as adenoid hypertrophy or rhinosinusitis [31]. The most common patient complaints include bilateral purulent rhinorrhea and nasal obstruction. Epistaxis, recurrent rhinosinusitis, halitosis, and otitis media with or without effusion may also occur in cases of prolonged nasopharyngeal lodgment [30].

\section{Conclusion}

Nasopharyngeal foreign body aspiration is a rare event, but it should be considered as a potential diagnosis in patients presenting with persistent symptoms or new complaints with a positive history of foreign body aspiration.

\section{Conflicts of Interest}

The authors declare that there are no conflicts of interest regarding the publication of this article.

\section{References}

[1] H. K. Tan, K. Brown, T. McGill et al., "Airway foreign bodies (FB): a 10-year review," International Journal of Pediatric Otorhinolaryngology, vol. 56, no. 2, pp. 91-99, 2000. 
[2] L. J. Hoeve, J. Rombout, and D. J. Pot, "Foreign body aspiration in children. The diagnostic value of signs, symptoms and pre-operative examination," Clinical Otolaryngology, vol. 18, no. 1, pp. 55-57, 1993.

[3] J. Reilly, J. Thompson, C. MacArthur et al., "Pediatric aerodigestive foreign body injuries are complications related to timeliness of diagnosis," Laryngoscope, vol. 107, no. 1, pp. 17-20, 1997.

[4] E. Svedström, U. Puhakka, and P. Kero, "How accurate is chest radiography in the diagnosis of tracheobronchial foreign bodies in children?," Pediatric Radiology, vol. 19, no. 8, pp. 520-522, 1989.

[5] A. B. Silva, H. R. Muntz, and R. Clary, "Utility of conventional radiography in the diagnosis and management of pediatric airway foreign bodies," Annals of Otology, Rhinology, and Laryngology, vol. 107, no. 10, pp. 834-838, 1998.

[6] R. L. Wesenberg and J. Blumhagen, "Assisted expiration chest radiography. An effective technique for the diagnosis of foreign body aspiration," Radiology, vol. 130, no. 2, pp. 538-539, 1979.

[7] P. T. Farrell, "Rigid bronchoscopy for foreign body removal: anaesthesia and ventilation," Pediatric Anesthesia, vol. 14, no. 1, pp. 84-89, 2004.

[8] A. Martinot, M. Closset, C. H. Marquette et al., "Indications for flexible versus rigid bronchoscopy in children with suspected foreign-body aspiration," American Journal of Respiratory and Critical Care Medicine, vol. 155, no. 5, pp. 1676-1679, 1997.

[9] A. F. Inglis Jr. and D. V. Wagner, "Lower complication rates associated with bronchial foreign bodies over the last 20 years," Annals of Otology, Rhinology, and Laryngology, vol. 101, no. 1, pp. 61-66, 1992.

[10] D. W. Vane, J. Pritchard, C. W. Colville et al., "Bronchoscopy for aspirated foreign bodies in children. Experience in 131 cases," Archives of Surgery, vol. 123, no. 7, pp. 885-888, 1988.

[11] O. Dikensoy, C. Usalan, and A. Filiz, "Foreign body aspiration: clinical utility of flexible bronchoscopy," Postgraduate Medical Journal, vol. 78, no. 921, pp. 399-403, 2002.

[12] B. F. Rothmann and C. R. Boeckman, "Foreign bodies in the larynx and tracheobronchial tree in children. A review of 225 cases," Annals of Otology, Rhinology, and Laryngology, vol. 89, no. 5, pp. 434-436, 1980.

[13] M. Francois, Thach-Toan, D. Maisani, C. Prévost, and P. Roulleau, "Endoscopy for exploration for foreign bodies of the lower respiratory tract of the child. Apropos of 668 cases," Annales d Otolaryngologie et de Chirurgie Cervico-Faciale, vol. 102 , no. 6, pp. 433-441, 1985.

[14] S. Eren, A. E. Balci, B. Dikici et al., "Foreign body aspiration in children: experience of 1160 cases," Annals of Tropical Paediatrics, vol. 23, no. 1, pp. 31-37, 2003.

[15] E. M. Burton, W. G. Brick, J. D. Hall et al., "Tracheobronchial foreign body aspiration in children," Southern Medical Journal, vol. 89, no. 2, pp. 195-198, 1996.

[16] L. Mu, P. He, and D. Sun, "Inhalation of foreign bodies in Chinese children: a review of 400 cases," Laryngoscope, vol. 101, no. 6, pp. 657-660, 1991.

[17] H. Schmidt and B. C. Manegold, "Foreign body aspiration in children," Surgical Endoscopy, vol. 14, no. 7, pp. 644-648, 2000.

[18] A. O. Ciftci, M. Bingöl-Koloğlu, M. E. Senocak et al., "Bronchoscopy for evaluation of foreign body aspiration in children," Journal of Pediatric Surgery, vol. 38, no. 8, pp. 1170-1176, 2003.
[19] J. Ransome, "Foreign bodies in the nose," in Scott Brown's Otolaryngology, A. G. Kerra and J. Groves, Eds., vol. 6, pp. 276-279, Butterworth and Co, London, UK, 5th edition, 1987.

[20] F. Karakoç, B. Karadağ, C. Akbenlioğlu et al., "Foreign body aspiration: what is the outcome?," Pediatric Pulmonology, vol. 34, no. 1, pp. 30-36, 2002.

[21] W. Aparna, G. Christina, S. A. Philips et al., "An audit of morbidity and mortality associated with foreign body aspiration in children from a tertiary level hospital in Northern India," African Journal of Paediatric Surgery, vol. 11, no. 4, pp. 287-292, 2014.

[22] D. Blair, R. Kim, N. Mills, C. Barber, and M. Neeff, "A heuristic approach to foreign bodies in the paediatric airway," International Journal of Pediatric Otorhinolaryngology, vol. 78, no. 12, pp. 2262-2266, 2014.

[23] B. Tokar, R. Ozkan, and R. Ilhan, "Tracheobronchial foreign bodies in children: importance of accurate history and plain chest radiography in delayed presentation," Clinical Radiology, vol. 59, no. 7, pp. 609-615, 2004.

[24] C. Y. Chiu, K. S. Wong, S. H. Lai, S. H. Hsia, and C. T. Wu, "Factors predicting early diagnosis of foreign body aspiration in children," Pediatric Emergency Care, vol. 21, no. 3, pp. 161-164, 2005.

[25] S. K. Aggarwal, S. K. Sinha, S. K. Ratan et al., "Complications of long-standing foreign body in the airway and their outcomes after endoscopic management: an experience of 20 cases," Journal of Laparoendoscopic and Advanced Surgical Techniques, vol. 25, no. 1, pp. 81-87, 2015.

[26] M. Liancai, H. Ping, and S. Degiang, "The causes and complications of late diagnosis of foreign body aspiration in children," Archives of Otolaryngology-Head and Neck Surgery, vol. 117 , no. 8 , pp. 876-878, 1991.

[27] F. Ogut, M. Bereketoglu, C. Bilgen et al., "A metal ring that had been lodged in a child's nasopharynx for 4 years," Ear, Nose, and Throat Journal, vol. 80, no. 8, pp. 520-521, 2001.

[28] S. Mahmood and G. E. Lello, "Tooth in the nasopharynx," British Journal of Oral and Maxillofacial Surgery, vol. 40, no. 5, pp. 448-449, 2002.

[29] C. Bilgen, B. Karci, and U. Uluoz, "A nasopharyngeal mass: leech in the nasopharynx," International Journal of Pediatric Otorhinolaryngology, vol. 64, no. 1, pp. 73-76, 2002.

[30] R. D. Briggs, A. M. Pou, and N. R. Friedman, "An unusual catch in the nasopharynx," American Journal of Otolaryngology, vol. 22, no. 5, pp. 354-357, 2001.

[31] F. Eghtedari, "Long lasting nasopharyngeal foreign body," Otolaryngology-Head and Neck Surgery, vol. 129, no. 3, pp. 293-294, 2003. 


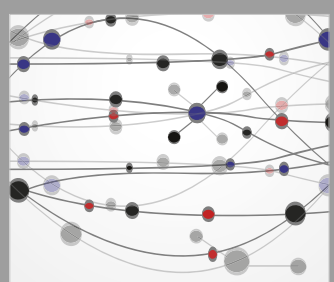

The Scientific World Journal
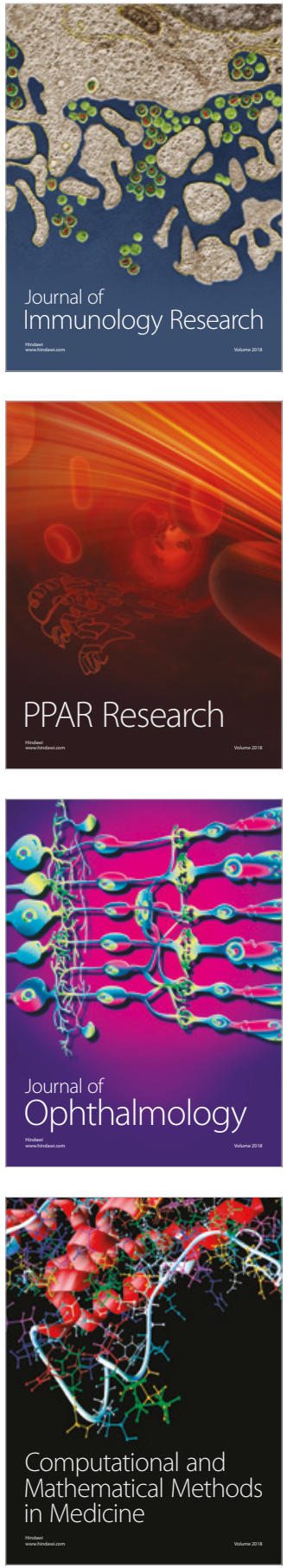

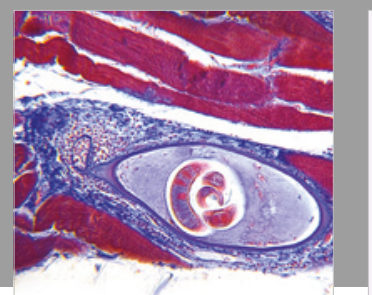

Gastroenterology Research and Practice

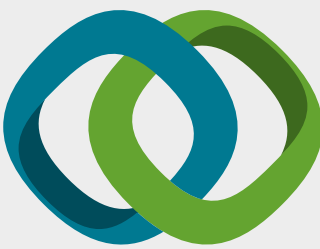

\section{Hindawi}

Submit your manuscripts at

www.hindawi.com
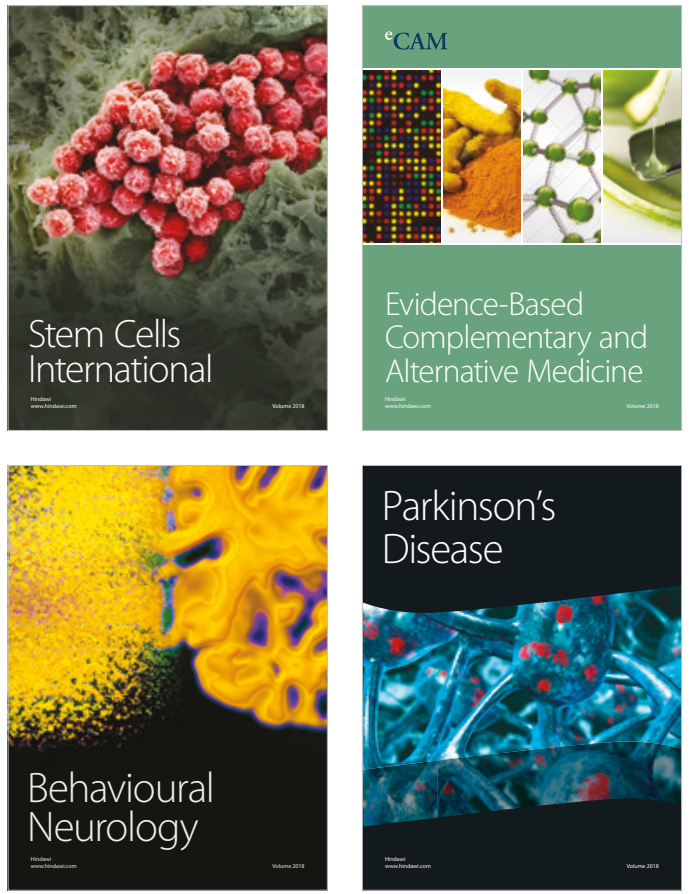

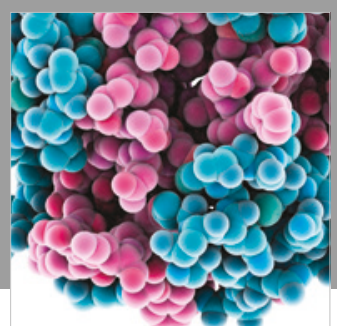

ournal of

Diabetes Research

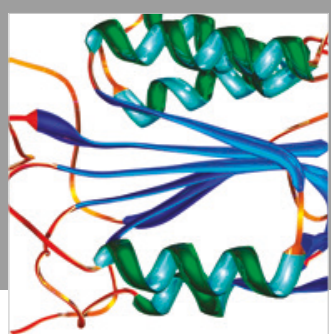

Disease Markers
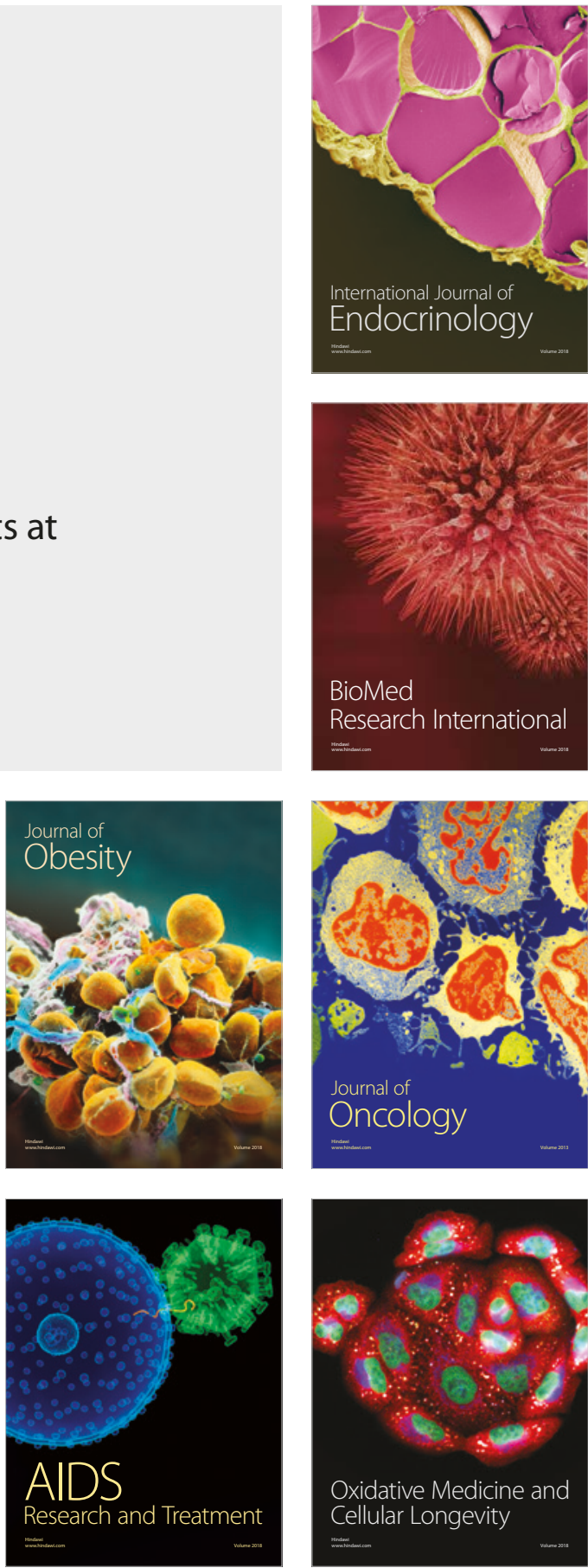